\title{
Integrating Design Throughout the Curriculum Using Case Studies S. Lambert*\$steve@uwaterloo.ca
}

Engineering design is a systematic, interdisciplinary process, which considers the requirements and impacts of our products and processes throughout their life-cycle. These products and processes are complex, and good designers must be able to handle this complexity, and work in interdisciplinary teams to develop a successful result. Many approaches are possible to develop good design engineers. The University of Waterloo has had since its founding in 1957 a core philosophy based on co-operative education, in which students alternate work terms with academic terms throughout their career. This provides an excellent opportunity for students to develop professional skills necessary for engineering practice and design. Recently, a new program has been introduced at Waterloo as part of the NSERC Chairs in Design Engineering program. This program aims to evolve the co-operative education model, by developing engineering case studies from student work term experience and implement them throughout the engineering curriculum. This makes available some of the design engineering experience of our students to others, to further enrich and integrate design engineering throughout the curriculum.

Design case studies are a representation of a real engineering challenge, with real data and real constraints, and real results. They provide an opportunity for students to assess and appreciate real engineering situations, and develop skills to approach problems with the right level of analysis and creativity. They are an excellent learning tool; they can provide motivation and context for engineering principles covered in all courses, not just specialized design courses. However, this approach requires a critical mass of good engineering cases, covering a broad range of engineering concepts and applications. Creating these cases is a challenge. However, students in the Waterloo co-op program are already required to document their work term experience in the form of a work term report. Collectively, our students produce approximately 4000 of these reports every year. 